\title{
THE CONTRIBUTION MODELLING GASOLINE INJECTION AT ENGINES WITH SPARK LIGHTING \\ ${ }^{I}$ V. Blaga, ${ }^{2}$ C. Daroczi \\ ${ }^{1}$ University of Oradea, Universitatii Street 1, 410087, Oradea, Romania, e-mail:vblaga@uoradea.ro \\ e-mail:kdaroczi@uoradea.ro
}

\begin{abstract}
The authors present the general aspects of theoretical modeling of gasoline injection, the principle modeling of some of the elements of gasoline injection, namely the gasoline pump model and the pressure regulator model. It is presented the general model of a spark engine with gasoline injection. The modeling of the motor cycles with spark engines and gasoline injection suggested by the authors is realized by executing a computer program for determining the variation of the three-dimensional and bi-dimensional parameters with the sub-programs: program for calculating the SIE (dependence according to $\mathrm{n}$ and $\lambda$ at $\mathrm{t}_{\mathrm{o}}=-35 \ldots+45^{\circ} \mathrm{C}$ and $\mathrm{p}_{\mathrm{o}}=1 \cdot 10^{2} \mathrm{kPa}$ ); program for calculating the SIE (dependence according to $n$ and $t_{o}$ at $\lambda=1$ and $p_{o}=1 \cdot 10^{2} \mathrm{kPa}$ );program for calculating the SIE cycle with gasoline injection. It was realized a study for calculating the pressure from the admission gallery $\mathbf{p}_{\mathbf{g a}}$ and the admission pressure $\mathbf{p}_{\mathbf{a}}$.
\end{abstract}

Keywords: pressure regulator, valve, pulverization, duration of injection.

\section{INTRODUCTION: GENERAL ASPECTS OF THE MODELLING}

The theoretical and experimental research of the elements and injection systems of gasoline, represent the fundamental components of the analysis and synthesis for knowing the static and dynamic quality performances. The experimental analysis takes place mainly when the system in known, while the theoretic one when we design the system. The usage of computer in modeling the systems considerably enlarges the possibility for studying a of a great number of models in a short period of time, and then through simulation we can follow the answer when applying different entering signals [1].

In the analysis and the synthesis in dynamic running of the injection systems for gasoline we usually use a series of laws, theorems, fluid mechanic and mathematics.

About the mathematical means, we can say that in the majority of the cases the differential equations systems which describe the phenomena which take place inside the injection systems of the gasoline are non-linear.

There is no universally applicable methodology for solving these non-linear equations, so we solve them through approximation, which allow the description of the phenomena to the prejudice of the quality of the simulation.

Among the most frequently used methods we can mention:

Linearization of calculating relation around a functioning stationary point; linear analysis on parts; analysis in the plan of phases; Analysis with description function.

In order to illustrate the linearization method we will present Taylor's formula for a function with two variables. With the help of this formula we can linearize any of the functions around a point [7].

Being given a function $f(x, y)$, which in the neighborhood of $(a, b)$ has continuous partial derivates of $(n+1)$ order, according to Taylor's formula, can be written:

$$
\begin{aligned}
& \mathrm{f}(\mathrm{x}, \mathrm{y})=\mathrm{f}(\mathrm{ab})+\frac{1}{1 !}\left[\mathrm{f}_{\mathrm{x}}^{\prime}(\mathrm{a}, \mathrm{b}) \cdot(\mathrm{x}-\mathrm{a})+\mathrm{f}_{\mathrm{y}}^{\prime}(\mathrm{a}, \mathrm{b})(\mathrm{y}-\mathrm{b})\right]+\frac{1}{2 !}\left[\mathrm{f}_{\mathrm{xx}}^{\prime \prime}(\mathrm{a}, \mathrm{b})(\mathrm{x}-\mathrm{a})^{2}(\mathrm{y}-\mathrm{b})+2 f_{x y}^{\prime \prime}(a, b)(x-a)(y-b)+\right. \\
& \left.+\mathrm{f}_{\mathrm{yy}}^{\prime \prime}(\mathrm{a}, \mathrm{b})(\mathrm{y}-\mathrm{b})^{2}\right]+\ldots+\frac{1}{\mathrm{n} !}\left[(\mathrm{x}-\mathrm{a}) \frac{\partial}{\partial \mathrm{x}}+(\mathrm{y}-\mathrm{b}) \frac{\partial}{\partial \mathrm{y}}\right]^{\mathrm{n}} \mathrm{f}(\mathrm{a}, \mathrm{b})+\mathrm{R}_{\mathrm{n}}(\mathrm{x}, \mathrm{y}) ; \\
& \text { where }: \mathrm{R}_{\mathrm{n}}(\mathrm{x}, \mathrm{y})=\frac{1}{(\mathrm{n}+1) !}\left[(\mathrm{x}-\mathrm{a}) \frac{\partial}{\partial \mathrm{x}}+(\mathrm{y}-\mathrm{b}) \frac{\partial}{\partial \mathrm{y}}\right]^{\mathrm{n}+1} \cdot f[a+\theta(x-a), b+\theta(y-b)], O \prec \theta \prec 1
\end{aligned}
$$

Where: in the particular case $a=b=0$ : we obtain Mac Laurin's formula. Structurally, a system of gasoline injection from an engine represents a succession of energy conversions $\mathrm{C} 1, \mathrm{C} 2, \ldots, \mathrm{C} 5$, Fig. 1 . In the figure the blocks represent, in order: the electric motor drive EMD, the gasoline pump PB, control and adjustment 
equipment $\mathrm{ARC}$, (directional equipment for flow regulation and pressure storage, filtering, injection), usually named the organs of the spark ignition engine ESL.

The electric engine is accumulator driven. It transforms the electric energy into mechanic energy, so here takes place the first conversion $\mathrm{C} 1$, and then the gasoline pump transforms the mechanic energy into pressure potential energy, in this way the second conversion takes place $\mathrm{C} 2$. The electromagnetic injector pulverizes and doses the gasoline in front of the admission valve realizing in this way the conversion of the pressure potential energy and electromagnetic energy into mechanic energy for moving the needle/indicator of the $\mathrm{C} 3$ injector. In the combustion chamber of the engine takes place a double energy conversion. When the fuel mixture burns the chemical energy of the fuel is conversed into thermal energy $\mathrm{C} 4$, which is transformed into effective work (mechanic energy) and the C5 conversion takes place.

Compared with other systems in a classical acceptation having an entering amount $\mathrm{x}_{\mathrm{i}}$ and an outgoing amount $\mathrm{x}_{\mathrm{e}}$, Fig. 1. The system of gasoline injection is presented in systemic acceptation, like a multivariable system in which the component elements (blocks 1...n) are quadric-poles or sexa-poles, and the connection lines (poles) represent the information support of the variables, Fig. 2.

The global driving system supposes the existence of an electric amount (U-voltage, I-intensity), mechanic ( $\mathrm{n}_{1}$ - the pump's number of rotations); $\mathrm{n}(\mathrm{v})$ - number of rotations of the ESL; M1 - the moment of the pump; $\mathrm{M}(\mathrm{F})$ - the moment of the ESL, and hydraulics $\left(\mathrm{Q}_{\mathrm{p}}\right.$ - the pump's flow rate; $\mathrm{Q}_{\mathrm{M}}$ the air flow rate at the ESL; pp- pressure of the pump; pM- the pressure at the MAS) ordered in such a way according to the way of transmission of the energy or information. The amounts $U, n_{1}, Q_{p}, Q_{M}$, and $n(v)$ are called direct variables or movement variables, through which the frequency characteristic of the system is made, while $\mathrm{M}(\mathrm{F}) ; \mathrm{p}_{\mathrm{M}} ; \mathrm{p}_{\mathrm{p}} ; \mathrm{M}_{1} ; \mathrm{I}$ - are called effort variables, which supposes the power supply of the system for creating the force or the necessary moment for surmounting of resistant moments or forces from the engine. $\mathrm{X}$ and F' are exterior amounts for command. From the global system presented in Fig. 1 we can distinguish the system made by the $2,3,4$, blocks, which are in fact the injection system of the gasoline, having the mechanic connections at entrance $\mathrm{n} 1$ and $\mathrm{M}_{1}$; and $\mathrm{n}(\mathrm{v})$ and $\mathrm{M}(\mathrm{F})$ with four energy conversions at the exit. This subsystem is analyzed on each of its components.

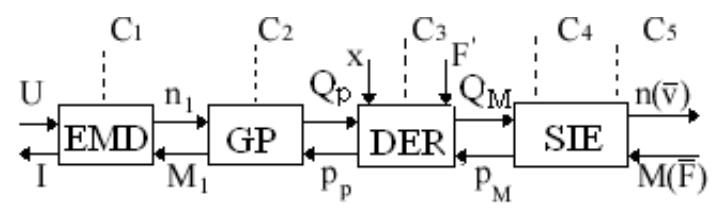

Figure 1. The scheme of the energy conversions for an injection system

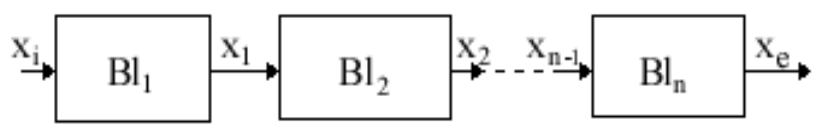

Figure 2. The multi variable system for gasoline injection

\section{THE PRESSURE CALCULUS FROM THE ADMISSION GALLERY $P_{\text {Ga }}$ AND THE ADMISSION PRESSURE $\mathbf{P}_{\mathrm{A}}$}

Taking into consideration the admission process on a short length of time, applied the equation of Bernoulli to the gas flow, written for the entering section in the admission system $0-0$ and a section $1-1$ (Fig. 3) [5].

We write the equation of Bernoulli between the sections $0-0$ and $1-1$

$$
\frac{p_{o}}{\rho}=\frac{p_{g a}}{\rho}+\left(1+\xi_{g a}\right) \cdot \frac{W_{g a}^{2}}{2} ; \quad \mathrm{W}_{\mathrm{aer}}=0
$$

It results:

$$
\mathrm{p}_{\mathrm{ga}}=\mathrm{p}_{\mathrm{o}}-\left(1+\xi_{\mathrm{ga}}\right) \frac{\rho}{2} \cdot W_{g a}^{2}=p_{o}-1\left(1+\xi_{\mathrm{ga}}\right) \frac{\rho_{a e r}}{2} \cdot W_{g a}^{2}
$$


Where:

$\rho_{\mathrm{o}}=\rho_{\text {air }}$ is the density of the air (considered constant); $\rho=\gamma / g ; \mathrm{p}_{\mathrm{o}}-$ the from the entering section in the system; $\mathrm{p}_{\mathrm{ga}}$ - pressure from the admission gallery; $\mathrm{W}_{\mathrm{ga}}$ - the air flow speed through the admission gallery; $\xi_{\mathrm{ga}}-$ the coefficient of gas dynamic resistance of the admission gallery.

Applying the equation of continuity between the $1-1$ and $2-2$ sections it results:

$\mathrm{W}_{\mathrm{ga}} \cdot \mathrm{A}_{\mathrm{s}}=\mathrm{W}_{\mathrm{a}} \cdot \mathrm{A}_{\mathrm{c}} ; \quad \mathrm{A}_{\mathrm{s}}=\pi \mathrm{d}_{\mathrm{o}}{ }^{2} / 4 ; V_{s}=A_{c} \cdot S \Rightarrow A_{c}=\frac{V_{s}}{S} ;$

$\mathrm{S}$ - the stroke of the piston $[\mathrm{m}]$;

$$
\begin{gathered}
W_{a}=W_{p m}=\frac{1}{30} \cdot S \cdot n ; W_{g a}=W_{a} \frac{A_{c}}{A_{s}}=\frac{1}{30} \cdot S \cdot n \cdot \frac{V_{s}}{S} \cdot \frac{1}{\frac{\pi d_{o}{ }^{2}}{4}} \\
W_{g a}=\frac{4}{30 \cdot \pi} \cdot n \cdot \frac{V_{s}}{d_{o}{ }^{2}} ; p_{g a}=p_{o}-\left(1+\xi_{g a}\right) \cdot \frac{\rho_{a e r}}{2} \cdot\left(\frac{4}{30 \pi}\right)^{2} \cdot n^{2} \cdot\left(\frac{V_{s}}{d_{o}^{2}}\right)^{2} ;
\end{gathered}
$$

A) The case when the density of the engine fluid $\rho$ is constant

$$
p_{g a}=p_{o}-k_{1}\left(1+\xi_{g a}\right) \cdot n^{2} \cdot\left(\frac{V_{s}}{d_{o}^{2}}\right)^{2}
$$

Where: $\mathrm{k}_{1}=\frac{\rho_{\text {aer }}}{2} \cdot\left(\frac{4}{30 \pi}\right)^{2}$

In which: $A_{s}$ - the area of the free section near the valve; $V_{s}$ - unitary capacity; $S$ - the stroke of piston; $A_{c}$ - the area of transversal section of the cylinders; $\mathrm{W}_{\mathrm{a}}$ - the air speed in the cylinder; $\mathrm{W}_{\mathrm{pm}}$ - medium speed of the piston; $d_{o}-$ diameter of the admission gallery; $n$ - the number of rotations of the crank shaft;

We write the equation of Bernoulli between the sections $1-1$ and $2-2$ [4]:

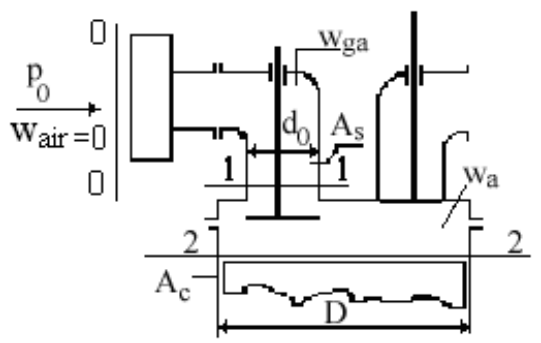

Figure 3. The scheme for analytic calculus of al $p_{g a}$ and $p_{a}$

$$
\begin{gathered}
\frac{p_{g a}}{\gamma}+\frac{W_{g a}^{2}}{2 g}=\frac{p_{a}}{\gamma}+\left(1+\xi_{a}\right) \frac{W_{a}^{2}}{2 g} \\
\mathrm{p}_{\mathrm{a}}=\mathrm{p}_{g a}+\frac{\gamma}{2 \mathrm{~g}} W_{g a}^{2}-\left(1+\xi_{a}\right) \frac{\gamma}{2 g} W_{a}^{2}
\end{gathered}
$$

Where: $\xi_{a}=c_{a}-$ the coefficient of gas dynamic resistance of the admission way:

$$
W_{g a}=\frac{4}{30 \pi} \cdot n \cdot \frac{V_{s}}{d_{o}^{2}} ; \quad \mathrm{W}_{\mathrm{a}}=\frac{\mathrm{S} \cdot \mathrm{n}}{30} ; \mathrm{S}=\frac{\mathrm{V}_{\mathrm{s}}}{\mathrm{A}_{\mathrm{c}}}=\frac{V_{s}}{\frac{\pi D^{2}}{4}}=\frac{4 V_{s}}{\pi D^{2}} ; \mathrm{W}_{\mathrm{a}}=\frac{4}{30 \pi} \cdot n \cdot \frac{V_{s}}{D^{2}} ;
$$




$$
\begin{gathered}
p_{a}=p_{g a}+\frac{\rho_{a e r}}{2} \cdot\left(\frac{4}{30 \pi}\right)^{2} \cdot n^{2} \cdot\left(\frac{V_{s}}{d_{o}^{2}}\right)^{2}-\left(1+\xi_{a}\right) \frac{\rho_{a e r}}{2}\left(\frac{4}{30 \pi}\right)^{2} \cdot n^{2} \cdot\left(\frac{V_{s}}{D^{2}}\right)^{2} ; \\
p_{a}=p_{g a}-k_{1} \cdot n^{2} \cdot V_{s}^{2}\left[\left(1+\xi_{a}\right) \frac{1}{D^{4}}-\frac{1}{d_{o}^{4}}\right] .
\end{gathered}
$$

It results, the expression of the admission pressure:

$$
\begin{gathered}
p_{a}=p_{g a}-k_{1} \cdot n^{2} \cdot \frac{V_{s}^{2}}{d_{0}^{4}}\left[\left(1+\xi_{a}\right)\left(\frac{d_{o}}{D}\right)^{4}-1\right] \\
\text { if: }\left[\left(1+\xi_{a}\right)\left(\frac{d_{o}}{D}\right)^{4}-1\right]>0 ;\left(1+\xi_{a}\right)\left(\frac{d_{o}}{D}\right)^{4}>1 ; \Rightarrow \xi_{\mathrm{a}}>\frac{1}{\left(\frac{\mathrm{d}_{\mathrm{o}}}{\mathrm{D}}\right)^{4}}-1 .
\end{gathered}
$$

For the Dacia Logan vehicle the ratio $\frac{d_{o}}{D}=0,42 ; \xi_{\mathrm{a}}$ - the coefficient of gas dynamic resistance of the admission way;

$\xi_{a}>\frac{1}{0,42^{4}}-1 ; \xi_{\mathrm{a}}>32 .[7]$

By using gasoline injection, the gas dynamic resistence of the admission way is smaller than at the classical engines, where the carburetor and its diffuser introduce a gaso dynamic resistance 8-10 times greater.

B) The case when the density of engine fluid $\rho$ is variable [3].

Bernoulli's relation between the section $0-0$ and $2-2$ in this case becomes:

$$
\begin{gathered}
p_{o}=p_{a}+(1+\xi a) \frac{\rho_{a}}{2} \cdot W_{a}^{2} ; \rho_{\mathrm{a}}=\frac{\mathrm{p}_{\mathrm{a}}}{\mathrm{RT}_{\mathrm{a}}} \\
\mathrm{W}_{\mathrm{a}}=\mathrm{W}_{\mathrm{p}}=\frac{\mathrm{n}}{30} S=\frac{n}{30} \frac{V_{s}}{A c}=\frac{4}{30 \pi} \cdot \frac{V_{s}}{D^{2}} \cdot n ; \\
\mathrm{a}_{\mathrm{sa}}=\sqrt{k_{a} \cdot R T_{a}} \Rightarrow R T_{a}=\frac{a_{s a}^{2}}{k_{a}} ; \rho_{\mathrm{a}}=\frac{k_{a}}{a_{s a}{ }^{2}} \cdot p_{a} ; \\
p_{o}=p_{a}+\left(1+\xi_{a}\right) \frac{k_{a}}{2} \cdot \frac{1}{a_{s a}^{2}} \cdot p_{a} \cdot\left(\frac{4}{30 \pi}\right)^{2} \cdot\left(\frac{V_{s}}{D^{2}}\right)^{2} \cdot n^{2} \\
p_{o}=p_{a}\left[1+\left(1+\xi_{a}\right) \frac{k_{a}}{2} \cdot\left(\frac{4}{30 \pi}\right)^{2} \cdot\left(\frac{V_{s}}{D^{2}}\right)^{2} \cdot\left(\frac{n}{a_{s a}}\right)^{2}\right] \\
p_{a}=\frac{1+\left(1+\xi_{a}\right) \frac{k_{a}}{2} \cdot\left(\frac{4}{30 \pi}\right)^{2} \cdot\left(\frac{V_{s}}{D^{2}}\right)^{2} \cdot\left(\frac{n}{a_{s a}}\right)^{2} \cdot p_{o}=k_{1} \cdot p_{o}}{1+\left(1+\xi_{a}\right) \cdot \frac{k_{a}}{2} \cdot\left(\frac{4}{30 \pi}\right)^{2} \cdot\left(\frac{V_{s}}{D^{2}}\right)^{2} \cdot\left(\frac{n}{a_{s a}}\right)^{2}}
\end{gathered}
$$

Where:

$\mathrm{a}_{\mathrm{sa}}$ - the speed of the sound in the fluid at the admission in the cylinders; $\mathrm{k}_{\mathrm{a}}$ - the medium adiabatic exponent of the admission;

$\mathrm{p}_{\mathrm{a}}$ - admission pressure. 
Bernoulli's equation between section $0-0$ and $1-1$ will be:

$$
p_{o}=p_{g a}+\left(1+\xi_{g a}\right) \cdot \frac{\rho_{g a}}{2} \cdot W_{g a}{ }^{2} ; \rho_{g a}=\frac{p_{g a}}{R T_{g a}}=\frac{p_{g a}}{R T_{o}},
$$

Where:

$\rho_{\mathrm{ga}}$ - pressure from the admission gallery; $\mathrm{T}_{\mathrm{o}}-$ temperature of the environment; $\mathrm{T}_{\mathrm{ga}}-$ temperature in the admission gallery.

Applying the relation for the continuity of the mass flow we determine:

$$
W_{g a} \cdot A_{s} \cdot \rho_{g a}=W_{a} \cdot A_{c} \cdot \rho_{a}
$$

$\mathrm{W}_{\mathrm{ga}}-$ the speed of gas flow in the admission gallery will be:

$$
\begin{gathered}
W_{g a}=\frac{A_{c}}{A_{s}} \cdot \frac{\rho_{a}}{\rho_{g a}} \cdot W_{a}=\frac{\pi D^{2}}{4} \cdot \frac{4}{\pi d_{o}{ }^{2}} \cdot \frac{p_{a}}{p_{g a}} \cdot \frac{R T_{o}}{R T_{a}} \cdot W_{a} ; \\
\mathrm{W}_{\mathrm{ga}}=\frac{\mathrm{D}^{2}}{\mathrm{~d}_{\mathrm{o}}{ }^{2}} \cdot \frac{p_{a}}{p_{g a}} \cdot \frac{T_{o}}{T_{a}} \frac{4}{30 \pi} \cdot \frac{V_{s}}{D^{2}} \cdot n=\frac{4}{30 \pi} \cdot \frac{p_{a}}{p_{g a}} \cdot \frac{T_{o}}{T_{a}} \cdot \frac{V_{s}}{d_{o}{ }^{2}} \cdot n ;
\end{gathered}
$$

By introducing the $\mathrm{W}_{\mathrm{ga}}$ in Bernoulli's equation written for sections $0-0$ and $1-1$ it results: [5]

$$
\begin{aligned}
& p_{o}=p_{g a}+\left(1+\xi_{g a}\right) \frac{p_{g a}}{2 R T_{o}} \cdot\left(\frac{4}{30 \pi}\right)^{2} \cdot\left(\frac{p_{a}}{p_{g a}}\right)^{2} \cdot\left(\frac{T_{o}}{T_{a}}\right)^{2} \cdot\left(\frac{V_{s}}{d_{o}^{2}}\right)^{2} \cdot n^{2} \\
& p_{o}=p_{g a}+\left(1+\xi_{g a}\right) \frac{1}{2 R T_{a}} \cdot\left(\frac{4}{30 \pi}\right)^{2} \cdot \frac{p_{a}{ }^{2}}{p_{g a}} \cdot \frac{T_{o}}{T_{a}} \cdot\left(\frac{V_{s}}{d_{o}^{2}}\right) \cdot n^{2}
\end{aligned}
$$

We introduce the relation: $\mathrm{RT}_{\mathrm{a}}=\frac{\mathrm{a}_{\mathrm{sa}}^{2}}{\mathrm{k}_{\mathrm{a}}}$

$$
p_{o} \cdot p_{g a}=p_{g a}{ }^{2}+\left(1+\xi_{g a}\right) \frac{k_{a}}{2 a_{s a}^{2}} \cdot\left(\frac{4}{30 \pi}\right)^{2} \cdot k_{1}^{2} \cdot p_{o}^{2} \cdot \frac{T_{o}}{T_{a}} \cdot\left(\frac{V_{s}}{d_{o}^{2}}\right)^{2} \cdot n^{2}
$$

We write: $\mathrm{p}_{\mathrm{a}}=\mathrm{k}_{1} \cdot p_{o} ; p_{g a}{ }^{2}-p_{o} \cdot p_{g a}+k_{2} \cdot p_{o}{ }^{2}=0$.

We solve the second degree equation, with the unknown $\mathrm{p}_{\mathrm{ga}}$, where:

$$
\begin{aligned}
& k_{2}=\frac{k_{a}}{2} \cdot k_{1}^{2}\left(1+\xi_{g a}\right) \cdot\left(\frac{4}{30 \pi}\right)^{2} \cdot \frac{T_{0}}{T_{a}} \cdot\left(\frac{V_{s}}{d_{o}^{2}}\right)^{2} \cdot\left(\frac{n}{a_{s a}}\right)^{2} ; \quad \mathrm{k}_{2}>0 ; \\
& p_{g a_{1,2}}=\frac{p_{0} \pm \sqrt{p_{0}^{2}-4 k_{2} \cdot p_{0}^{2}}}{2}=\frac{p_{0} \pm p_{0} \sqrt{1-4 k_{2}}}{2}=\frac{p_{0}\left(1 \pm \sqrt{1-4 k_{2}}\right)}{2} ; \mathrm{k}_{2}>0 ; \\
& \sqrt{1-4 \mathrm{k}_{2}} \geq 0 \Rightarrow 0 \leq k_{2} \leq \frac{1}{4} ; \mathrm{k}_{2}=0 ; \mathrm{n}=0 ; \Rightarrow \mathrm{p}_{\mathrm{ga}}=\frac{\mathrm{p}_{0}(1+1)}{2}=p_{0} .
\end{aligned}
$$

The solution is:

$$
p_{g a}=\frac{1+\sqrt{1-4 \mathrm{k}_{2}}}{2} p_{o}=k_{3} \cdot p_{o}
$$


Where: $k_{3}=\frac{1+\sqrt{1-4 \mathrm{k}_{2}}}{2}$.
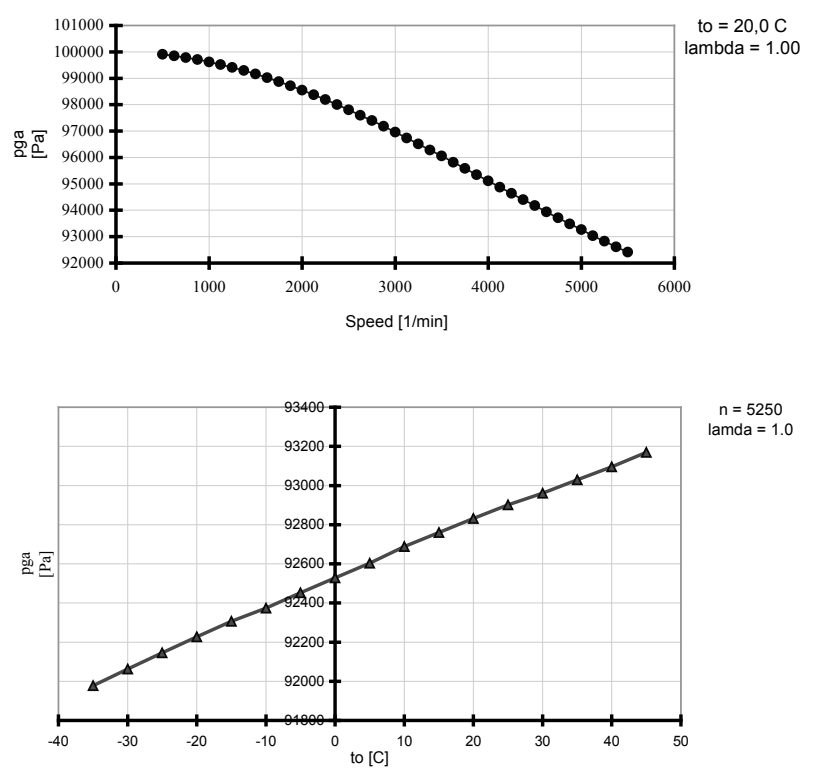

Figure 4. Variation of the pressure from the admission gallery $p_{g a}$ with the number of rotations $n$ and the temperature of the environment $t_{0}$
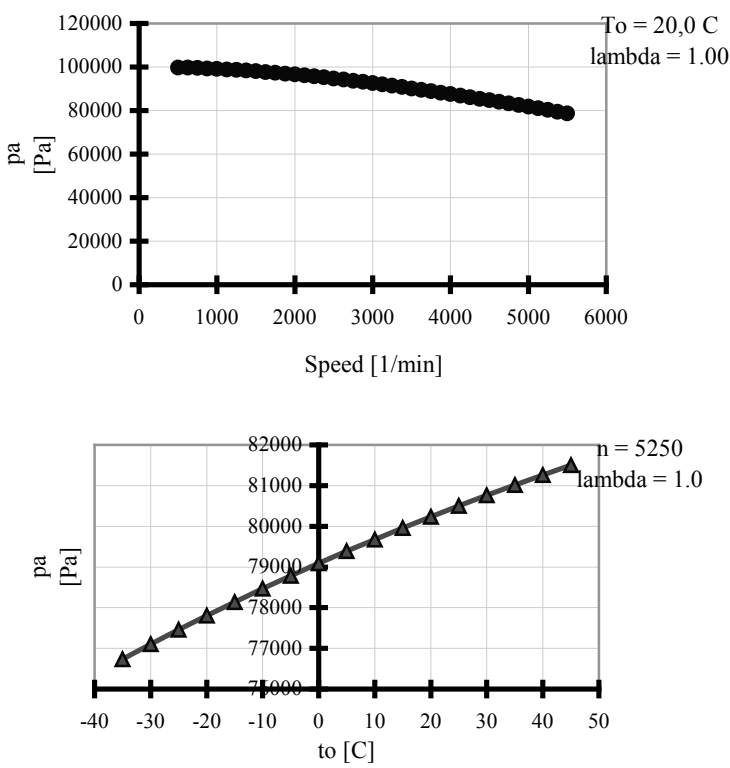

Figure 5. Variation of admission pressure $p_{a}$ with the number of rotations $n$ and temperature of the environment $t_{0}$

Fig. 4 presents the pressure variation from the admission gallery pga with the number of rotations and temperature of the environment, and Fig. 5 presents the admission pressure variation pa with the number of rotations and temperature of the environment from the calculus program. 


\section{CONCLUSIONS}

a, It was devised a personal model for calculating the pressure for the admission gallery pga and for the pressure at the end of admission pa.

$\mathrm{b}$, It was devised the model for calculating the MAS parameters with the gasoline injection with the subprograms: program for calculus of MAS parameters (dependence after $n$ and $\lambda$ at $t_{0}=-35 \ldots+45^{\circ} \mathrm{C}$ and $\mathrm{p}_{\mathrm{o}}=1 \cdot 10^{2} \mathrm{kPa}$;

The program for calculating the parameters of the SIE (dependence on $n$ and $t_{0}$ at $\lambda=1$ and $\mathrm{p}_{0}=1 \cdot 10^{2} \mathrm{~Pa}$ ); the program calculating the SIE cycle at the gasoline engine;

c, With the help of the calculus program, we figured the three-dimensional of the adiabatic and polytrophic coefficients, temperatures and pressure in the characteristic points of the cycle, the filling coefficient, the dosage, the heat supply of the capacity of the engine, the pressure growth ratio in the isochoric burning, the volume growth ratio in post burning, the technical-economical parameters of the engine and the length of the injection.

\section{REFERENCES}

[1] Apostolescu, N. \& Chiriac, R., ( 1998). The Process of burning in driving with inward alight. The Technical Edition, Bucharest. ISBN 973-31-0646-1

[2] Bataga, N.,(1979). Driving with inward alight. The Didactic Publishing house and Pedagogical, Bucharest.

[3] Bica, A. M.; Curila, M.; Curila, S. (2013). The method of successive interpolations solving initial value problems for second order functional differential equations, Fixed Point Theory, , ISSN 1583-5022, Volume 14 (2013), Issue. 1, pp. 67-89

[4] Bica, A. M.; Curila, M.; Curila, S. (2012). About a numerical method of successive interpolations for functional Hammerstein integral equations, Journal of Computational and Applied Mathematics, , ISSN 1583-5022, Volume 236 (2012), Issue. 7, pp. 2005-2024

[5] Blaga, V.,(2000). The modeling injection from gasoline at engines with spark lightning through sparking. The University Editor from Oradea, ISBN 973-8083-41-9.

[6] Blaga, V., (2005)Engine with gasoline injection, The University Edition Oradea. ISBN 973- 613981-6.

[7] Grünwald, B.,(1980). The Theory, calculation and construction engine's for road motor vehicle. The Didactic Publishing house and Pedagogical Bucharest. 